\title{
Antennal epicuticular structure of camel crickets (Orthoptera: Rhaphidophoridae) for identifying the prey of Mustella sibrica Pallas
}

\author{
Chun-Yu Hu${ }^{1}$, Jeng-Tze Yang ${ }^{1,2^{*}}$, Wu-Chun $\mathrm{Tu}^{1}$ \\ ${ }^{1}$ Department of Entomology, National Chung-Hsing University, Taichung, Taiwan; \\ *Corresponding Author: jtyang@dragon.nchu.edu.tw \\ ${ }^{2}$ Department of Plant Medicine, National Pingtung University, Pingtung, Taiwan
}

Received 27 May 2013; revised 14 August 2013; accepted 21 August 2013

Copyright (c) 2014 Chun-Yu Hu et al. This is an open access article distributed under the Creative Commons Attribution License, which permits unrestricted use, distribution, and reproduction in any medium, provided the original work is properly cited. In accordance of the Creative Commons Attribution License all Copyrights @ 2014 are reserved for SCIRP and the owner of the intellectual property Chun-Yu Hu et al. All Copyright (C 2014 are guarded by law and by SCIRP as a guardian.

\section{ABSTRACT}

Camel crickets (Orthoptera: Rhaphidophoridae) are a group of wingless and humpbacked Orthopteran insects. They are closed relatives to katydids and crickets; they were called spider crickets somewhere because of their long legs. Camel cricket plays an important role in the food web in various ecosystems. In the forest ecosystem, they live in the ground level of forestry under litters and fallen leaves, and some of them live beneath the log and hid themselves under loosen tree barks. They feed on decomposing organic substances and serve as decomposers in the food chain. It is a very common insect prey to insectivorous animals in natural and artificial vegetation. Guandaushi (GDS) is the experimental forest station of National Chung Hsing University, as the study site of long term ecological research (LTER) in Taiwan. And the camel cricket became an important subject and a dominant insect group in the LTER studies. They are the major parts of the insect preys of vertebrates, especially to the insectivorous mammals. According to our previous publication, $32.2 \%$ of the insect preys of Mustela sibirica Pallas are camel crickets in GDS forest ecosystem. There were 5 morpho-species of camel crickets by the characters of antennal epicuticular characters. The camel cricket was collected from various ways according to the LTER study during 19951998. The morphology of antennal epicuticular structure from totally 60 individuals was observed by using SEM. The epicuticular sculpture was described and classified into Type I and Type II by the SEM photographs. Type I has 8 patterns and Type II has 5 patterns in this study. The illustration and the pictorial key were provided here as the tool for further application. The morphospecies could not be identified due to the remainder being fragmented while examined. After the study, the SEM antennal epicuticular structures were classified and identified based upon the antennae sample of the morphospecies from the specimens of the 5 camel crickets which were collected from GDS forest ecosystem in this study. This is a part of the fundamental study for the protocol of ecosystem study. The protocol for identifying the insectivorous animal's prey by the insect fragment of food remainders is necessary. One more, there were 7 of the 13 patterns of antennal epicuticular structure applied to analysis the 5 morpho-species provided as the case study for taxonomy.

\section{KEYWORDS}

Camel Crickets; Antennal Epicuticle; Ultra-Structure; Insectivorous; Prey

\section{INTRODUCTION}

The surfaces of insect antennae with various structures, such as sensory organs, hairs setae etc. are important and good characters to taxonomy. We used to describing some special and distinguishable structure applied as good diagnostic characters for the identification. There are many previous studies reported on antennal sensory plaque organs in the taxonomy and phylogeny of fulgoroi- 
dea of homoptera [1,2]. And recently, antennal sensory organ classified and evaluated as the taxonomic characters of nocturnal moth by SEM photography is published by our team [3]. Antennal epicuticular structure has been served as insect taxonomic character since long time ago, but not until the practice of the techniques of SEM and TEM, the ultra fine structure becomes possible in many other studies. In general, the number and the position or distribution type of cuticular receptors were used as important characters or land marks structures while studying on antennal morphology [4,5]. The identification using antennal structure is fairly common in identifying some groups of insects such as thrips, spring tails, dipterans etc., but not so common in identifying the fragments which mixed in the inclusion of food remainders pieces by pieces from mammal's digestive ducts or the animal feces. This paper is an application of insect integument structure for investigating the prey of insectivorous animals. Moreover, to establish the character library in such detail, fine scale is special for identifying the fragmented pieces of remainders obtained from the mammal's digestive ducts or their feces.

Camel crickets, Rhaphidophoridae belonging to Orthoptera are a group of middle size insects in Taiwan; the body size in general, is about $30 \mathrm{~mm}$ in length. Filiform antennae are about 3 - 5 times longer than body length. Most camel crickets are humpbacked, and both male and female are wingless. The habitats of them are known as living on damp humus, and sometimes in rock caves or tree caves as well. Camel crickets are scavengers or saprophagous [6].

According to Yang et al. [7] and $\mathrm{Hu}$ [8], the most parts of insect fragments in the feces of Mustela sibirica Pallas, 1977 (Carnivora: Mustelidae) and in digestive tracts of Crocidura tadae kurodai Jameson \& Jones, 1977 (Insectivora: Soricidae) are Rhaphidophoridae in Guandaushi forest ecosystem. Obviously, camel crickets are significant keystone species for insectivorous mammals in GDS forest ecosystem. This study will be very helpful in such food chain or food web investigation to analyze the trophic circulation in the ecosystem.

\section{MATERIALS AND METHODS}

The study was conducted at the Guandaushi forest $\left(24^{\circ} 04^{\prime} \mathrm{N}, 121^{\circ} 01^{\prime} \mathrm{E}\right)$, Huisun Experimental Forest Station of National Chung Hsing University, Nantou. The camel crickets specimens were collected by pitfall traps $(24 \times 15$ $\times 11 \mathrm{~cm}$ ) and fragments were collected from the feces of Mustela sibirica Pallas, 1977 (Carnivora: Mustelidae) while the Long Term Ecological Research investigated the insectivores animal's prey insects (Table 1 ). All the possible specimens became as available in this study. We tend to provide the taxonomic identification tools for the ap- plied entomological study in the future.

Preparation: The procedures for preparing to collect the antennal of camel cricket are described as following.

1) Antennal Sample: Cutting off 5 - 10 segment of antenna from the individual specimen which was collected from field by pitfall trap, and put into 70\% alcohol solution for temporality preservation.

2) Cleaning: Ultrasonic $(43 \mathrm{KHz})$ for 15 minutes to clean up the specimens to get rid of the contamination on the surface.

3) Dehydration: A gradient series of acetone and alcohol $(70 \%, 85 \%$, and $100 \%)$ at room temperature for dehydration.

4) Coating: Using gold in each specimen.

5) Observation: SEM (TOPCON ABT-150s) applied for this study.

Measurement: The measuring parts and the landmarks of the process or producing on the antennal surface are shown in Figures 1 and 2. The surface and the face of electronic gun of SEM should be parallel to each other to prevent from the projection of the SEM photographs. The method followed previous study of Yang and Yen (2001) for sure the metric character is technically useful and reasonable.

\section{RESULTS AND DISCUSSION}

Five morpho-species of camel crickets have been found in this study (Table 1). However, it does not mean that there are 5 species of camel cricket in the LTER site, GDS subtropical forest ecosystem, Taiwan. The morphology of antennal epicuticular structure was observed by using SEM.

Totally 60 individuals were examined and described as detail as possible for the potential usage of the insectivores animal's prey study in the future. There were 13 patterns of antennal epicuticular structure discriminated from the various surface structures. They were classified as two main groups, Type I the lobe-like and Type II the setae-like. The lobe-like group, Type I including 8 types were subdivided into 2 subgroups: complete lobe (Type I a-1) and separate lobes (Type I b-1). The setae-like group, Type II including 5 patterns was divided into 3 subgroups, i.e., short setae-like, long ridged setae-like and needlelike surface sculptures. The arrays of the surface sculpture were distinguished and described as linear, reticular and sinuate types. This result will make the application of insect fragments identification for investigating the insectivore animal's prey became as possible and easier.

The patterns and array types of epicuticular structure could be the significant character sets for identifying camel crickets in GDS forest ecosystem. The key to types of antennal epicuticular structure of camel crickets in this study is provided in the following section (key to types and patterns of antennal epicuticular structure of camel 
Table 1. Camel cricket samples collected from pitfall traps in GDS forest ecosystem, 60 specimens.

\begin{tabular}{|c|c|c|c|c|c|c|c|c|}
\hline $\begin{array}{c}\text { coll. Date } \\
\text { (yyyy-mm-dd) }\end{array}$ & Sampling plot & coll. method & Phenon no. & morpho-species & $\begin{array}{c}\text { Antennal } \\
\text { Type/pattern }\end{array}$ & $\begin{array}{l}\text { Illust. Index } \\
\text { (Figure) }\end{array}$ & Elevation (m) & Notes (collector) \\
\hline 19980424 & $4-2$ & pitfall & 1 & sp1 & Ib-4 & F & 1100 & SH Wu \\
\hline 19980409 & $4-2$ & pitfall & 2 & sp1 & Ib-4 & $\mathrm{F}$ & 1100 & SH Wu \\
\hline 19980409 & $3-2$ & pitfall & 3 & sp1 & Ib-4 & $\mathrm{F}$ & 1200 & SH Wu \\
\hline 19980409 & $4-1$ & pitfall & 4 & sp1 & Ib-4 & F & 1100 & SH Wu \\
\hline 19980409 & $1-1$ & pitfall & 5 & sp1 & Ib-3 & E & 1150 & SH Wu \\
\hline 19980409 & $3-2$ & pitfall & 6 & sp2 & Ib-5 & G & 1200 & SH Wu \\
\hline 19980409 & $3-2$ & pitfall & 7 & sp2 & Ib-5 & G & 1200 & SH Wu \\
\hline 19980730 & $4-3$ & pitfall & 8 & sp2 & Ib-5 & G & 1100 & SH Wu \\
\hline 19980730 & $4-3$ & pitfall & 9 & sp2 & Ib-5 & G & 1100 & SH Wu \\
\hline 19980730 & $1-3$ & pitfall & 10 & sp5 & Ib-2 & D & 1150 & SH Wu \\
\hline 19980730 & $4-2$ & pitfall & 11 & sp2 & Ib-5 & G & 1100 & SH Wu \\
\hline 19980409 & $1-1$ & pitfall & 12 & sp3 & Ib-5 & F & 1150 & SH Wu \\
\hline 19980730 & $2-3$ & pitfall & 13 & sp3 & Ia-2 & B & 1250 & SH Wu \\
\hline 19990425 & $8-2$ & pitfall & 14 & sp3 & Ib-4 & $\mathrm{F}$ & 1550 & SH Wu \\
\hline 19990425 & $8-2$ & pitfall & 15 & sp3 & Ib-4 & $\mathrm{F}$ & 1550 & SH Wu \\
\hline 19990425 & $9-5$ & pitfall & 16 & sp3 & Ib-4 & $\mathrm{F}$ & 1610 & SH Wu \\
\hline 19980428 & $1-1$ & pitfall & 17 & sp3 & Ib-4 & $\mathrm{F}$ & 1150 & SH Wu \\
\hline 19990425 & $\mathrm{I}-2$ & pitfall & 18 & sp4 & Ib-4 & $\mathrm{F}$ & ND & SH Wu \\
\hline 19990131 & $9-4$ & pitfall & 19 & sp4 & Ib-4 & $\mathrm{F}$ & 1610 & SH Wu \\
\hline 19990425 & $9-5$ & pitfall & 20 & sp4 & Ib-4 & $\mathrm{F}$ & 1610 & SH Wu \\
\hline 19990131 & $1-3$ & pitfall & 21 & sp5 & Ib-2 & D & 1150 & SH Wu \\
\hline 19990425 & $3-2$ & pitfall & 22 & sp1 & Ib-4 & F & 1200 & SH Wu \\
\hline 19990131 & $8-3$ & pitfall & 23 & sp4 & Ib-4 & $\mathrm{F}$ & 1550 & SH Wu \\
\hline 199808- & H30-3B & pitfall & 5-001 & sp5 & Ia-1 & A & 1500 & HY Wu \\
\hline 199808- & Н30-3В & pitfall & 6-002 & sp5 & Ia-2-1 & B-1 & 1500 & HY Wu \\
\hline 199710- & W40-1B & pitfall & 9-001 & sp1 ${ }^{*}$ & Ib-4 & $\mathrm{F}$ & 1350 & HY Wu \\
\hline 199710- & W40-3B & pitfall & $15-001$ & sp5 & Ia-1 & A & 1350 & HY Wu \\
\hline 199808- & H37-2B & pitfall & 26-002 & sp5 & Ia-1 & A & 1550 & HY Wu \\
\hline 199804- & H48-2B & pitfall & 52-005 & sp1* & Ib-4 & F & 1600 & HY Wu \\
\hline 199802- & L79-2B & pitfall & 133-001 & sp2 & Ib-4-1 & F-1 & 1550 & HY Wu \\
\hline 199712- & H30-2B & pitfall & 159-001 & sp5 & Ia-1 & A & 1500 & HY Wu \\
\hline 199712- & H37-1B & pitfall & 161-001 & Sp2 & Ib-4-1 & F-1 & 1550 & HY Wu \\
\hline 199712- & H48-1B & pitfall & $163-001$ & sp5 & Ia-1 & A & 1600 & HY Wu \\
\hline 199712- & L72-1B & pitfall & 172-001 & sp5 & Ib-2 & D & 1650 & HY Wu \\
\hline 199710- & H30-2B & pitfall & 177-001 & sp5 & Ia-1-1 & A-1 & 1500 & HY Wu \\
\hline 199810- & L97-1B & pitfall & 205-001 & sp5 & Ib-2 & $\mathrm{D}$ & 1680 & HY Wu \\
\hline 199810- & L97-1B & pitfall & 206-002 & sp5 & Ib-2 & D & 1680 & HY Wu \\
\hline 199810- & L97-1B & pitfall & 207-003 & sp1 ${ }^{*}$ & Ib-4 & $\mathrm{F}$ & 1680 & HY Wu \\
\hline 199810- & L97-2B & pitfall & 208-001 & sp5 & Ia-2- & B-2 & 1680 & HY Wu \\
\hline 199810- & L79-1B & pitfall & 209-001 & sp5 & Ia-2-2 & B-2 & 1550 & HY Wu \\
\hline 199810- & L26-3B & pitfall & 211-001 & sp5 & Ib-2 & D & 1610 & HY Wu \\
\hline 19971024 & $\mathrm{H} 40$ & remainder & 221-001 & $(\mathrm{sp} 1)^{* *}$ & Ib-3 & E & 1350 & JT Yang \\
\hline 19971217 & H09 & remainder & 237-001 & (sp5) & Ib-2 & D & 1400 & JT Yang \\
\hline 19960614 & H63-1 & remainder & $110-001$ & (sp 5) & Ia-1 & A & 1600 & JT Yang \\
\hline 19960728 & H63-1 & remainder & 122-001 & (Sp 5) & Ia-2-2 & B-2 & 1600 & JT Yang \\
\hline 19960730 & H60 & remainder & $126-002$ & (Sp 5) & Ia-2-2 & B-2 & 1600 & JT Yang \\
\hline 19961015 & H56 & remainder & $151-001$ & & Ib-1 & $\mathrm{C}$ & 1600 & JT Yang \\
\hline 19970813 & H58 & remainder & 206-001 & (sp5) & Ia-1 & A & 1600 & JT Yang \\
\hline 19971021 & LTER40 & remainder & 215-002 & (sp 5) & Ia-2-2 & B-2 & 1600 & JT Yang \\
\hline 19971214 & H46 & remainder & 227-000 & (sp 1) & Ib-3 & E & 1600 & JT Yang \\
\hline 19961017 & LTER82 & remainder & 153-002 & (sp 5) & Ia-1 & A & 1620 & JT Yang \\
\hline 19960813 & LTER49 & remainder & 204-002 & (sp 5) & Ia-1 & A & 1630 & JT Yang \\
\hline 19971217 & LTER49 & remainder & 239-000 & (sp 1) & Ib-3-1 & E-1 & 1630 & JT Yang \\
\hline 19960723 & LTER67 & remainder & $120-003$ & (sp 5) & Ia-1 & A & 1640 & JT Yang \\
\hline 19960912 & LTER82 & remainder & 127-002 & (sp 5) & Ia-2-1 & B-1 & 1650 & JT Yang \\
\hline 19971024 & LTER90 & remainder & 222-001 & (sp 1?) & Ib-3-2 & E-2 & 1670 & JT Yang \\
\hline 19971216 & LTER90 & remainder & 236-002 & (sp 1) & Ib-3 & E & 1670 & JT Yang \\
\hline 19980212 & LTER90 & remainder & 249-002 & (sp 1?) & Ib-3-2 & E-2 & 1670 & JT Yang \\
\hline 19970319 & LTER105 & remainder & 185-001 & - & Ib-6 & $\mathrm{H}$ & 1700 & JT Yang \\
\hline 19971214 & LTER99 & remainder & 232-002 & (Sp1) & Ib-3 & E & 1690 & JT Yang \\
\hline
\end{tabular}

${ }^{* *}$ The morpho-species could not identify due to the remainder is fragmented while examined. After the study, compared to the SEM antennal epicuticular structures classification and identify to the morpho-species shown in parenthesis ( ). ${ }^{* * * *}$ The SEM observation only by fragment and not able to identify to morpho-species known in this study. 
width

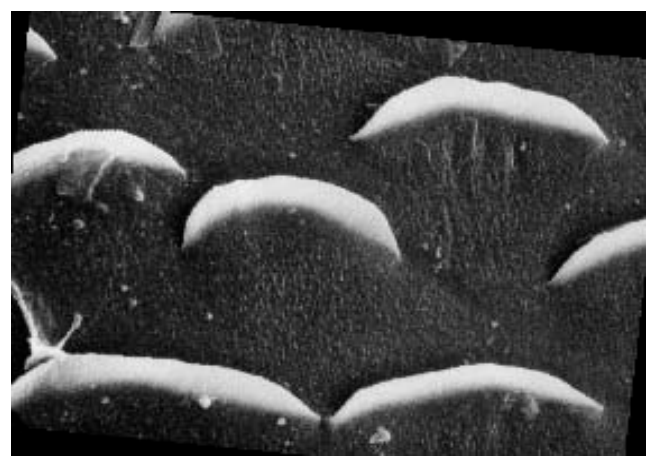

Figure 1. The land marks for measuring the antennal epicuticular structure of complete lobe-like patterns (Type I).

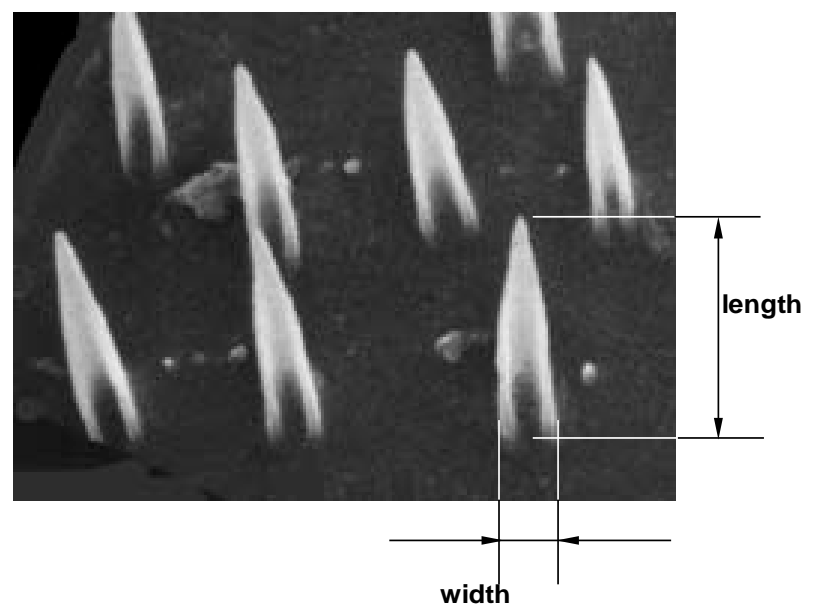

Figure 2. The land marks for measuring the antennal epicuticular structure of setae-like patterns (Type II).

crickets in GDS forest ecosystem). It is useful to other relevant studies, such as food web of terrestrial predator project study. There have been many projects under Long Term Ecological Research (LTER) in GDS forest ecosystem focused on insectivorous animal's feeding behavior like as Kam et al. [9], Yang et al. [7] and Hu et $a l$. [10]. In general, animal prey investigation is based on the community inventory, but the accuracy prey which is intaken by predators must be evident by remainder in feces or inclusions in digestive ducts. This study used both the material collected directly from the remainder and from the pitfall trapped camel crickets for comparison and it makes the study possible from both remainder of feces and inclusions of intestine and fauna inventory. The camel cricket is common and dominant ground living insects in different ecosystem. The antenna fragments remanded in both feces and digestive ducts as the dominant parts of insect fragments. The materials are easy to collect for identification. The antennal surface is easier to observe by SEM. The characters of the epicuti- cular structure were defined in this paper and classified as 13 patterns. The morpho-species could not be identified due to the remainder is fragmented while examined. After the study (Table 1), compared to the SEM antennal Epicuticular structures classification and identify to the morpho-species are shown in the Table 1. However, some SEM observation is lacking the comparison from the pitfall trapped specimen and still not able to identify to morpho-species in this study. Significantly, the community inventory is some very supported background information in this case. As a biological taxonomist, we would like to suggest the fauna inventory and taxonomic revision work is very important for such applied ecological studies.

It makes identification become as much easier while study on the feeding behavior of insectivore animals. In addition, this study could provide some information and inspiration for the taxonomic study of Rhaphidophoridae to find and evaluate the better and good characters for diagnosis in between species and developing stages by the intra-specific variations.

Key to types and patterns of antennal epicuticular structure of camel crickets (Orthoptera: Rhaphidophoridae) in GDS forest ecosystem:

1a Antennal epicuticular surface sculpture in lobe like - 2

$1 \mathrm{~b}$ Unlike above --------------------------------- 9

2a Each surface sculpture with single complete lobe --- 3

$2 \mathrm{~b}$ Each surface sculpture comprising of several separate lobes

3a Lobe surface sculpture wider than middle long about 5.1: $1.0(n=3)$ (Figure 3(a)) ------------ Type I a-1 $3 \mathrm{~b}$ Lobe surface sculpture wider than middle long about 9.4: $1.0(n=1)$ (Figure 3(b)) ------------- Type I a-2 4a Margin of lobe surface sculpture round -------------- 5 4b Margin of lobe surface sculpture angulate or irregular

5a Surface sculpture comprises of 3 - 5 separate lobes, some lobes with ridge indistinct (Figure 3(c))

Type I b-1

5b Surface sculpture comprise of 5 - 10 separate lobes, without ridge (Figure 3(d)) ----------------- Type I b-2 6a Setae-like surface sculpture in between lobes -------- 7 6b No-setae-like surface sculpture in between lobes ---- 8 7a Lobe surface sculpture without lanceolate surface sculpture (Figure 3(h)) ------------------ Type I b-6 7b Lobe surface sculpture mixed with lanceolate surface sculpture (Figure 3(g)) ------------------ Type I b-5 8a Indistinct margin of lobe surface sculpture free from antennal surface (Figure3(f)) --------------- Type I b-4 $8 \mathrm{~b}$ Distinct margin of lobe surface sculpture free from antennal surface (Figure 3(e)) ------------ Type I b-3 9a Needle-like or lanceolate surface sculpture arranged sinuately ------------------------------------------------ 10 9b Needle-like or lanceolate surface sculpture not arranged sinuately -------------------------------------------- 12 
10a Only short needle surface sculpture (Figure 3(i)) Type II a-1 10b Both short and long needle surface sculpture

11a Long needle about twice as long as short ones (Figure 3(j))
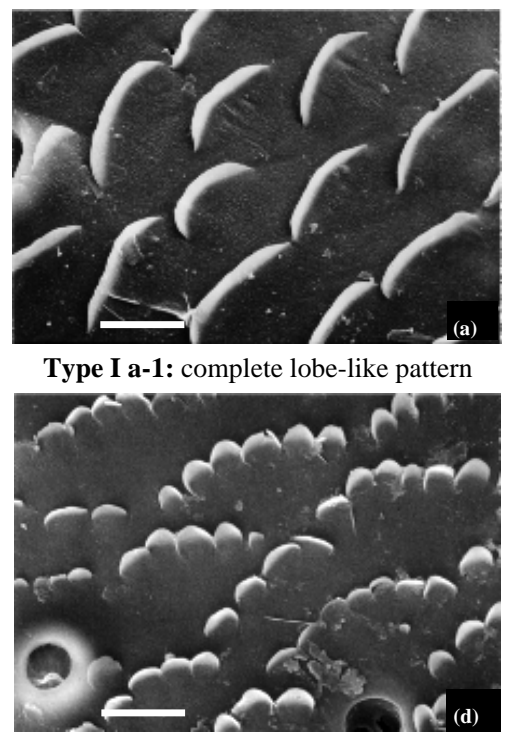

Type I b-2: more separate lobe- like pattern

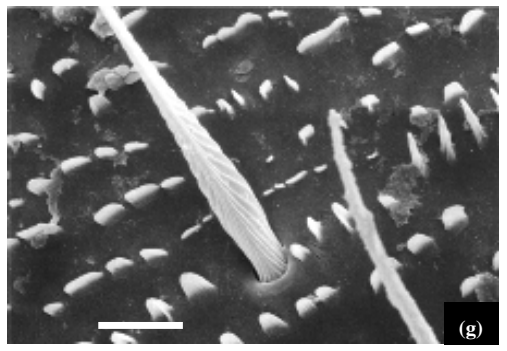

Type I b-5: lanceolate separate lobe-like patter

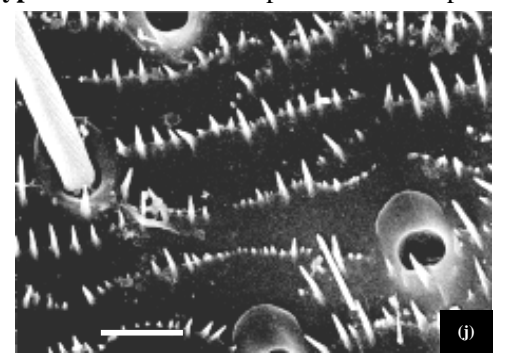

Type II b-1: middle setae-like pattern
Type II b-1

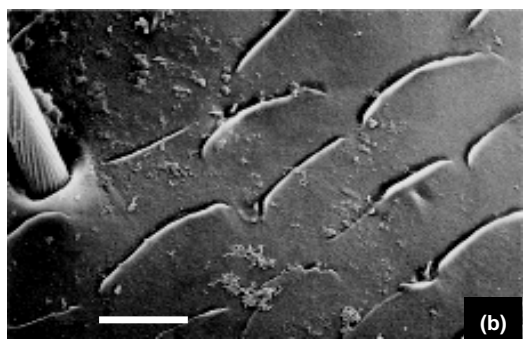

Type I a-2: short complete lobe- like pattern

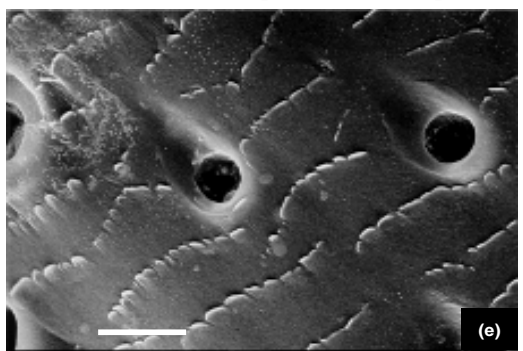

Type I b-3: tooth separate lobe- like pattern
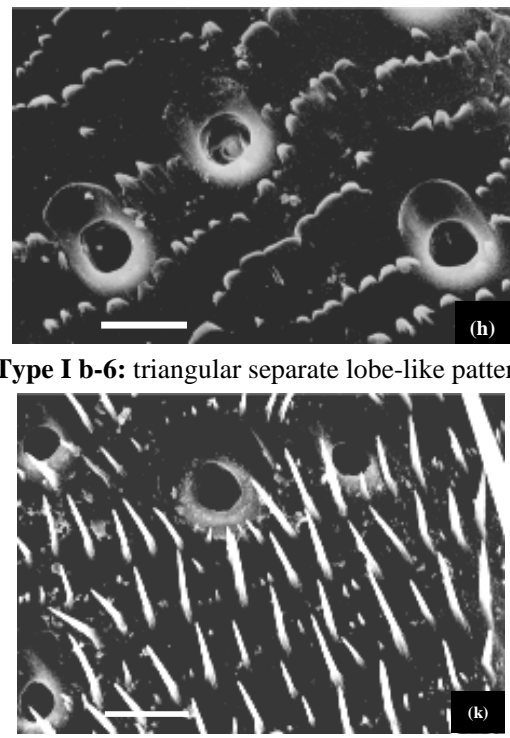

Type II b-2: long setae-like pattern

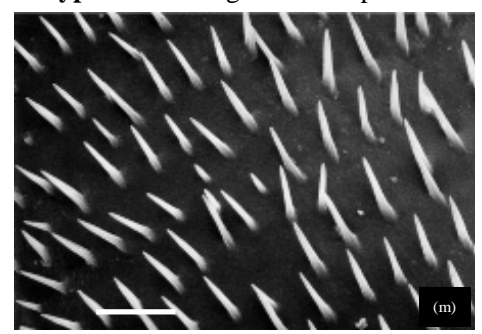

Type II c-2: needle-like pattern

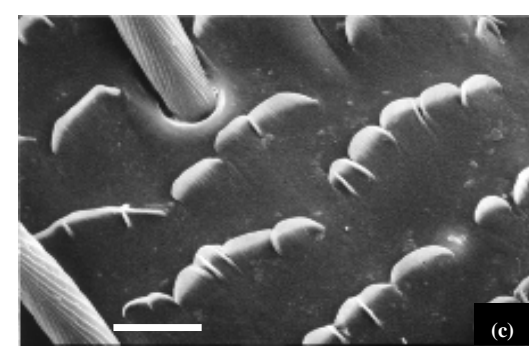

Type I a-2: short complete lobe- like pattern

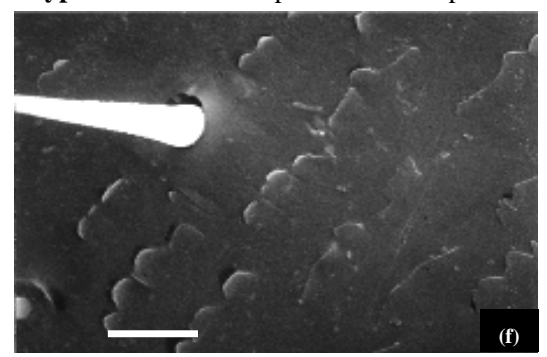

Type I b-3: tooth separate lobe- like pattern

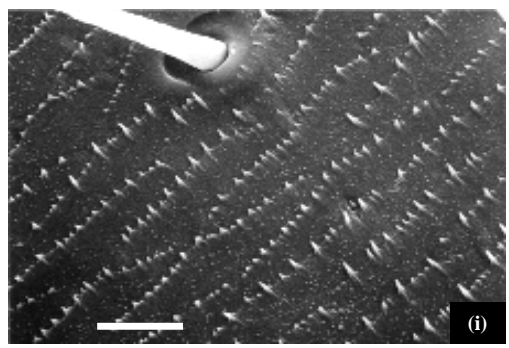

Type II a-1: short setae-like pattern

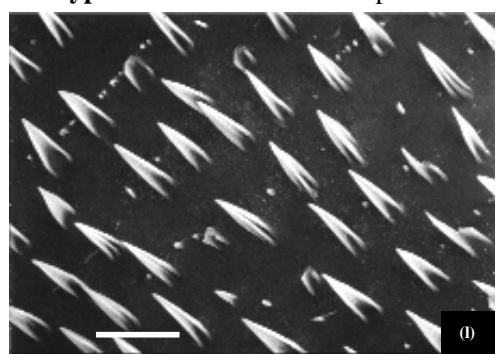

Type II c-1: long ridged setae- like pattern

Figure 3. Various types of antennal epicuticular structure of camel crickets (scale bar $=10 \mu$ ). 


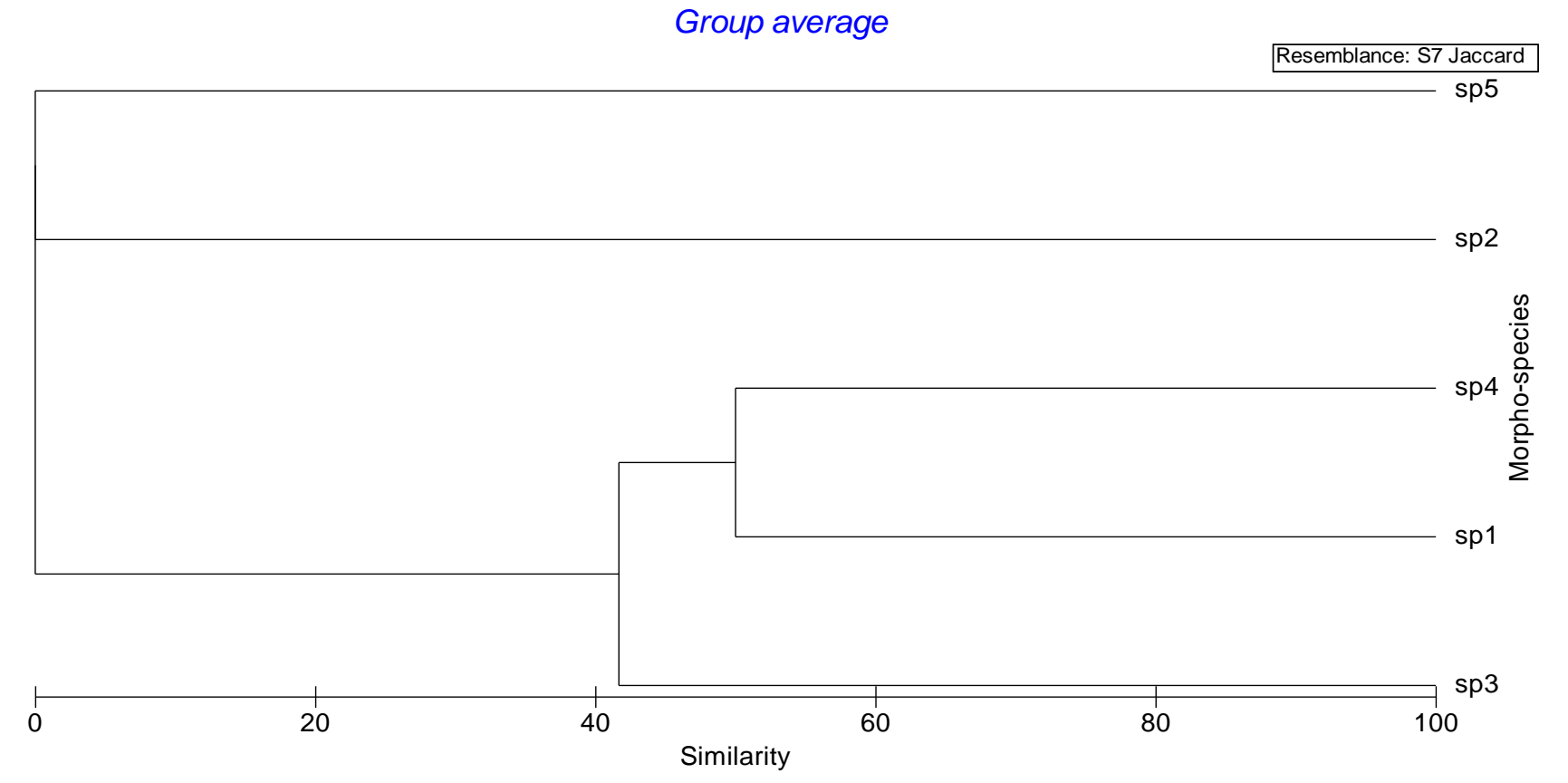

Figure 4. Apply the clustering analysis with Jaccard coeficience to analysis the 5 morpho-species by the 7 patterns of antennal epicuticular structure for example to show the usage of the potential taxonomic character which was provided in this paper. It is the case of application which based on the antennal epicuticular structure of camel crickets.

\section{CONCLUSIONS}

The camel cricket is sorted as 5 morpho-species by antennal epicuticular structure based on this study. However, the camel cricket fauna of GDS forest ecosystem is still unknown. It is necessary to do much effort to do the taxonomic revision to verify the fact of the camel cricket's biodiversity in the forest ecosystem. The variation of the SEM morphology is sorted as two types and each is with 5 and 8 patterns respectively.

It is just the basic taxonomic character description and definition for the insect diagnosis for both intra- and interspecies in morphology. Taxonomists have to evaluate the good character for good taxonomy based on this study. After the study, the SEM antennal Epicuticular structures classification made the identification of the materials from the remanded fragments to the morpho-species become possible which is shown in the Table 1 . The exception antennal pattern actually makes us aware that the community inventory to ecosystem study is supported background information in this protocol while the diet of insectivore animal's feeding behavior is studied. As a biological taxonomist, we would like to suggest and emphasize the fauna inventory and taxonomic revision work should be very important for such applied scientific studies.

So, the result of the SEM morphology in this paper is just served as basic and important data and information to the protocol for the taxonomist while applying the taxonomic methodology to do identification.
The clustering analysis for example is showing the further application's possibility to the antennal epicuticular structure (Figure 4). Although, the evaluation to such taxonomic characters is necessary while studying the revision work to camel crickets. This is the possible way for taxonomist to do co-laboratory study and publish paper with ecologist and others by sharing the credits.

\section{REFERENCES}

[1] Cheng, C.L. and Yang, C.T. (1996) Antennal sensory plaque organs of Fulgoridae (Homoptera: Fulgoroidea). Chinese Journal of Entomology, 16, 187-207.

[2] Shih, H.T. and Yang, C.T. (1996) Antennal sensory plaque organs of the Delphacidae (Homoptera: Fulgoroidea). Chinese Journal of Entomology, 16, 209-217.

[3] Aliou, D., Yang, J.T. and Lai, P.Y. (2013) Biomorphometric characteristics of different types of sensilla detected on the antenna of Helicoverpa armigera by scanning electron microscopy. Journal of Asia-Pacific Entomology, 16, 23-28. http://dx.doi.org/10.1016/j.aspen.2012.09.001

[4] Bland, R.G. (1991) Antennal and Mouthpart sensilla of tetrigidae (Orthoptera). Annals of the Entomological Society of America, 84, 197-200.

[5] Dickens, J.C., Hart, W.G., Light, D.M. and Jang, E.B. (1988) Tephritid olfaction: Morphology of the antennae of four tropical species of economic importance (Diptera: Tephritidae). Annals of the Entomological Society of America, 81, 325-331.

[6] Rentz, D.C.F. (1993) Orthopteroid insects in threatened habitats in Australia. Chapter 7. In: Gaston, K.J., New, T.R. 
and Samways, M.J., Eds., Perspectives in Insect Conservation, Andover, Hampshire, 125-138.

[7] Yang, J.T., Wu, H.Y. and Hu, C.Y. (1999) Preliminary report on the insect fragments in the feces of Mustela sibirica Pallas from Guandaushi forest ecosystem, central Taiwan. Quarterly Journal of Forest Research, 21, 1-7. (in Chinese with English abstract)

[8] Hu, C.Y. (2001) Analysis on the fragments of the insect prey for Mustela sibirica and Crocidura kurodai in Guandaushi forest ecosystem. Master's Thesis, National Chung Hsing University, 94. (in Chinese with English abstract).
[9] Kam, Y.C., Chen, T.C., Yang, J.T., Yu, F.C. and Yu, K.M. (1998) Seasonal activity, resproduction, and diet of a Riparian frog (Rana swinhoana) from a subtropical forest in Taiwan. Journal of Herpetology, 32, 447-452. http://dx.doi.org/10.2307/1565464

[10] Hu, C.Y., Yang, J.T. and Wu, H.Y. (2002) Analysis of insect fragments in the digestive tract contents of Crocidura tadae kurodai from the Guandaushi forest ecosystem, central Taiwan. Formosan Entomologist, 22, 147-155. (in Chinese with English abstract) 